\title{
O COTIDIANO DE PÓS-GRADUANDOS STRICTO SENSU EM ENFERMAGEM DE UMA UNIVERSIDADE FEDERAL
}

\author{
Vera Lucia Freitag ${ }^{1}$ \\ Bianca Contreira de Jung ${ }^{2}$ \\ Marcio Rossato Badke ${ }^{3}$ \\ Liamara Denise Ubessi ${ }^{4}$ \\ Marcos Aurélio Matos Lemões ${ }^{5}$ \\ Viviane Marten Milbrath ${ }^{6}$
}

\begin{abstract}
RESUMO
Introdução: Obter o grau acadêmico de mestre ou doutor implica alguns benefícios pessoais, profissionais e institucionais, mas para isso é necessário uma organização na vida em relação ao estudo, trabalho, lazer, descanso, família e alimentação, pois o vivido pelos estudantes faz com que haja uma mudança significativa no seu dia a dia. Objetivo: Conhecer o cotidiano de pós-graduandos do Programa de Pós-Graduação em Enfermagem (PPGEnf) de uma Universidade Federal do Sul do Brasil. Método: 0 estudo consiste em um relato de experiência realizado por alunos do PPGEnf e foi constituído por dois mestrandos e três doutorandos durante o mês de julho de 2014. Como método de investigação, utilizou-se a análise de conteúdo temática de Bardin. Resultados: Os estudantes vivenciam uma grande demanda da Pós-Graduação referente à escrita da dissertação e/ou tese, bem como a produção de artigos científicos. Esta demanda requer uma preocupação constante com a adequação a momentos para outras atividades, a fim de sair da rotina, como a rede familiar, os amigos, os momentos de lazer, descanso, atividades físicas. Há uma mudança na vida dos estudantes, fato que gera cobrança em muitos momentos por parte da família e dos amigos. Conclusão: Existe uma preocupação constante entre os estudantes referente à construção de seus projetos, no entanto encontram tempo para o lazer, o estar com a família, o estudar, existindo assim uma organização no cotidiano dos alunos. Espera-se com este estudo contribuir para uma reflexão dos alunos de Pós-Graduação na organização de suas atividades diárias.
\end{abstract}

Palavras-chave: Educação de Pós-Graduação em Enfermagem. Cuidado. Qualidade de vida. Estudantes. Enfermagem. Pesquisa em Enfermagem.

\section{THE QUOTIDIAN OF POST-GRADUATES STRICTO SENSU IN NURSING OF A FEDERAL UNIVERSITY}

\begin{abstract}
Introduction: To get the academic degree of master or doctorate implies some personal benefits, professional and institutional. But to do this, it is necessary an organization in life in relation to the study, work, leisure, rest, family and supply; therefore, the lived by students there is a significant change in its day to day. Objective: To recognize the daily routine of post-graduates in the Nursing Graduate Program (PPGEnf) of a Federal University of Southern Brazil. Method: The study consists of an experience report carried out by students in PPGEnf and was composed of two master students and three doctoral candidates during the month of July 2014. As a method of the research, we used the thematic content analysis of Bardin. Results: students experience a great demand of the graduate program regarding the writing of the dissertation and/or thesis, as well as the production of scientific articles. This demand requires a constant concern with the adequacy moments for other activities, in order to exit the routine, as the family network, friends, moments of leisure, rest, physical activities. There is a change in the life of the students, fact that generates collection at many moments on the part of the family and friends. Conclusion: There is a constant concern among students regarding the construction of its projects, however they find time for leisure, being with the family, the study, so there was an organization in the daily life of students. We hope to contribute to a reflection of the graduate students in the organization of their daily activities.
\end{abstract}

Keywords: Education Graduate Program in Nursing. Care. Quality of Life. Students. Nursing. Nursing Research.

\footnotetext{
${ }^{1}$ Enfermeira. Mestre em Ciências. Especialista em Gestão de Organização Pública em Saúde. Doutoranda em Enfermagem do Programa de Pós Graduação em Enfermagem da Universidade Federal do Rio Grande do Sul - PPGEnf/UFRGS. Bolsista pela Coordenação e Aperfeiçoamento de Pessoal de Nível Superior (Capes). Jaboticaba, Rio Grande do Sul - RS, Brasil. verafreitag@hotmail.com

${ }^{2}$ Enfermeira. Mestre em Ciências. Especialista em Gestão de Organização Pública em Saúde. Professora Substituta da Universidade Federal de Rio Grande - Furg, Pelotas, RS, Brasil. biajung@bol.com.br

${ }^{3}$ Enfermeiro. Mestre em Enfermagem. Doutorando do Programa de Pós Graduação em Enfermagem da Universidade Federal de Pelotas - PPGEnf/UFPel. Professor assistente do Departamento de Ciências da Saúde da Universidade Federal de Santa Maria (UFSM). Santa Maria, RS, Brasil.marciobadke@gmail.com

${ }^{4}$ Psicóloga, enfermeira. Doutoranda do PPGEnf/UFPel. Acadêmica de Filosofia UFPel. Bolsista pela Coordenação e Aperfeiçoamento de Pessoal de Nível Superior - Capes. Pelotas, RS, Brasil. liaubessi@gmail.com

${ }^{5}$ Enfermeiro. Doutorando em Enfermagem do PPGEnf/UFPel. Bolsista Capes. Rio Grande, RS, Brasil. enf.lemoes@gmail.com

${ }^{6}$ Enfermeira. Doutora em Enfermagem. Professora adjunta da Faculdade de Enfermagem da UFPel. Pelotas, RS, Brasil. vivianemarten@hotmail.com
} 
Programas de Pós-Graduação constituem condição fundamental para outorgar à Instituição de Ensino Superior o caráter universitário, o que a caracteriza como espaço de incremento para a ciência e a cultura (Rodrigues et al., 2008). O acesso a obras do mundo inteiro facilita a possibilidade de disseminação de conhecimento e, ao mesmo tempo, proporciona a construção do alicerce para o desenvolvimento da pesquisa, contribuindo para a expansão da base científica nacional. A vida em um mundo globalizado, no entanto, nem sempre permite um desfrute amplo da cultura (Brasil, 2014).

O preço para se garantir o acesso pode ser bastante elevado, assim como as leis e a tecnologia podem se configurar como guardiões dos bens culturais, podendo ser grandes entraves para o acesso ao conhecimento. Seu papel é social, e seu desempenho depende da mobilização da comunidade acadêmica e da integração entre a Coordenação de Aperfeiçoamento de Pessoal de Nível Superior (Capes) e o Conselho Nacional de Desenvolvimento Científico e Tecnológico (CNPq) (Rodrigues et al.; 2008; Brasil, 2014).

Em 2008 o Brasil dispunha de 32 Programas de Pós-Graduação Stricto sensu em Enfermagem, credenciados pela Capes, dos quais 18 em âmbito de Mestrado e 14 de Doutorado (Erdmann, 2008). Em maio de 2013 o panorama da Pós-Graduação contava com 63 programas Stricto sensu, totalizando 89 cursos, distribuídos por região: $2,3 \%$ no Norte; $20,2 \%$ no Nordeste; $9,0 \%$ no Centro-Oeste; $49,4 \%$ no Sudeste e $19,1 \%$ no Sul. Esse quantitativo representava $1,7 \%$ do total de cursos de Pós-Graduação brasileiros e 9,7\% dos da área de Ciências da Saúde (Scochi et al., 2013).

O objetivo principal do Stricto sensu é formar pesquisadores capazes de desenvolver, testar e intervir na realidade com o conhecimento de Enfermagem. Para tanto, é desejável que o estudante, além de competência, dedicação e maturidade, busque se capacitar para atuar como futuro pesquisador autônomo (Almeida et al., 2004); desenvolvendo, assim, a habilidade de construir novos conhecimentos.

O desafio das ciências em geral e da Enfermagem, em particular, é formar mestres e doutores com habilidades de pesquisadores e capacidade para trabalhar em parcerias com estudiosos dos melhores centros de pesquisa nacionais e internacionais (Brasil, 2009). Assim, é necessário que estes defendam uma ideia baseada no rigor científico e metodológico, de acordo com as exigências da Capes.

Atender à demanda de produção científica pela escrita de artigos, elaboração de projetos de pesquisas e socialização dos resultados requer um considerável esforço por parte dos pós-graduandos, fatores que alteram sua rotina diária. As exigências feitas na realização de um curso em nível Stricto sensu, seja de Mestrado ou Doutorado, requerem dedicação por parte dos estudantes, bem como uma organização da vida diária a fim de desfrutas de uma boa qualidade de vida.

Louzada e Silva Filho (2005) afirmam que a formação de um pesquisador se torna um agente estressor, podendo gerar sofrimento mental nos estudantes, pois vivem momentos de sofrimento e angústia, ocasionados pela pressão por publicação, excesso de atividades e regras a serem seguidas até tornarem-se pesquisadores independentes. Estes fatores associados, aliados ao investimento financeiro, causam o desgaste emocional.

Essas mudanças fazem com que o estudante viva períodos difíceis até adaptar-se à nova realidade, podendo ocorrer diversas reações diante das novas situações e dos desafios a que estão expostos (Osse; Costa, 2011). Estudo desenvolvido com acadêmicos da Graduação em Medicina aponta que as exaustões físicas e emocionais podem levar à despersonalização e à desistência do curso (Dyrbye et al., 2010). 
O contexto em que o pós-graduando brasileiro está inserido pode ser caracterizado por um alto nível de exigência por parte do programa, pelo fator excelência acadêmica, no que diz respeito aos aspectos qualitativos do seu trabalho, e, principalmente, pela pressão por resultados que levem à evidência quantitativa de seu currículo (Ciscon-Evangelista; Souza; Menandro, 2015).

Desse modo, conhecer como os estudantes vivem o seu cotidiano de pós-graduandos e sua vida paralelamente a isso, bem como ao fato de possuírem uma bolsa de estudos e ter ética para uma dedicação exclusiva no que diz respeito à realização da investigação e/ou produção científica corresponde a um trabalho baseado no comprometimento científico. Estudos como este pode contribuir para os programas de Pós-Graduação no campo da saúde, neste caso o da Enfermagem, que tem como pilares o desenvolvimento tecnológico e científico, o cuidado, a parceria entre ensino, pesquisa e extensão e o retorno do trabalho para a sociedade.

É importante que se busque em sua origem as raízes que possibilitaram o crescimento da Enfermagem como uma profissão, pois sua história e a dos cuidados foram escritas juntas (Budó, 2002). Cuidar implica ter intimidade, senti-las, acolhê-las, respeitá-las, dar-lhes sossego e repouso. Cuidar é entrar em sintonia com, auscultar-lhes o ritmo e afinar-se com ele. Tudo começa com o sentimento. É o sentimento que nos faz sensíveis ao que está à nossa volta, que nos faz gostar ou desgostar. É o sentimento que produz encantamento, pois nos une às coisas e nos envolve com as pessoas (Boff, 2014).

Nesse sentido, ao atuarmos na perspectiva da pesquisa, não podemos deixar de lado o nosso objeto de trabalho e o que o envolve - o cuidar. É preciso valorizar e incrementar esforços para que, na assistência, pesquisa ou gestão e, ainda, em qualquer outro segmento de trabalho, possamos (re)pensar as nossas práticas enquanto profissionais enfermeiros e capazes de transformação da realidade social. Diante disso, vê-se a importância de estudos como este, que podem instigar o estudante/profissional a um olhar reflexivo para o cuidado de si, reorganizando sua vida a fim de que seu dia a dia possa ser vivido de maneira que não cause sobrecarga de atividades.

Este estudo visa a contribuir para a comunidade acadêmica, pois o vivido pelos pós-graduandos em Enfermagem pode ir ao encontro do vivenciado por estudantes de outros cursos e, desta maneira, ajudar na reorganização de sua vida. A vivência no Stricto sensu é uma experiência, é um encontro pautado pelos órgãos fomentadores e regulamentadores, transformadora na vida dos estudantes. Também é uma forma de ampliação da capacidade para realização de pesquisas, condução e orientação de pessoas nessas processualidades, e de intervenção na realidade de modo a cumprir com a função social do que se pretende na condição de Universidade.

Isso posto, buscou-se descrever como é o cotidiano dos estudantes de Mestrado e Doutorado na organização do seu dia a dia, pois os estudos, o lazer, a família, a alimentação, são componentes que podem fazer parte desse cotidiano e contribuir ou não para a produção acadêmica e a qualidade de vida. Ao considerar estes aspectos, este estudo tem como objetivo conhecer o cotidiano de estudantes do Programa de Pós-Graduação em Enfermagem (PPGEnf) de uma Universidade Federal do Sul do Rio Grande do Sul.

\section{MÉTODO}

Trata-se de um estudo descritivo acerca de um relato de experiência vivenciado pelos estudantes do Programa de Pós-Graduação em Enfermagem (PPGEnf) de uma Universidade Federal do Sul do Rio Grande do Sul. Esta experiência relaciona-se à disciplina Pesquisa Qualitativa em Saúde, vinculada ao bloco com- 
plementar de disciplinas ofertadas no Mestrado Acadêmico, no período de abril a julho de 2014.

Com base neste aspecto, os alunos participantes da disciplina desenvolveram um trabalho focado no exercício de entrevistas, a partir das quais se produziu este relato de experiência, com a intenção de conhecer o cotidiano e sua implicação para a vida profissional e pessoal dos pós-graduandos.

Como fonte das informações para a sustentação da escrita deste artigo usou-se a entrevista semiestruturada, por considerá-la com um instrumento capaz de contemplar a possibilidade de fala e ser revelador das condições de vida das pessoas (Minayo, 2010). A entrevista semiestruturada incorporou aspectos como: a opção em cursar Mestrado/Doutorado; a organização do tempo para as atividades diárias, como períodos de estudo, de lazer, entre outras atividades; a relação com familiares e amigos; a alimentação e sobre o período de descanso e atividade física.

A escolha dos participantes ocorreu de forma intencional, com aqueles que apresentaram interesse na elaboração do artigo, ou seja, dois mestrandos que cursaram a disciplina e três doutorandos do programa de Pós-Graduação.

Os encontros para a coleta de dados foram realizados em uma sala de aula nas dependências da Universidade durante o mês de julho de 2014 e tiveram duração de aproximadamente três horas, em dois momentos. No primeiro momento foi apresentada a proposta de trabalho pelos mestrandos e feito convite aos alunos do Doutorado. Os estudantes que aceitaram participar foram convidados ao próximo momento: a realização das entrevistas semiestruturadas pelos alunos que cursavam a disciplina.

As entrevistas com os participantes foram efetivadas de modo individual em sala reservada da Universidade, local do estudo, por uma mestranda participante do estudo e, posteriormente, esta foi entrevistada pela professora me- diadora do estudo. Desta maneira, os participantes foram dois mestrandos, três doutorandos e uma professora que mediou o estudo. A pesquisa não necessitou de aprovação do Comitê de Ética em Pesquisa com Seres Humanos, visto que os participantes do estudo são também autores deste trabalho, entretanto foi solicitada a ciência formal dos participantes para gravação em meio digital. O diálogo foi transcrito em sua íntegra para que fosse possível analisar os elementos observados e contextualizados. As gravações foram integralmente transcritas e digitadas em um documento criado no programa Microsoft Office Word 2010®.

Dessa forma, emergiu uma categoria temática, caracterizada pelo conjunto de ideias com a finalidade de facilitar a compreensão (Bardin, 2011). Foram utilizados no corpo do texto fragmentos dos comentários dos participantes, identificados pela letra E, que se refere a Estudante e, consecutivamente, numerados conforme ordem da entrevista 1, 2,3, 4 e 5 .

\section{RESULTADOS E DISCUSSÃO}

Este artigo é constituído por um item: A organização na vida diária dos estudantes de Mestrado e Doutorado.

\section{A organização na vida diária dos estudantes de Mestrado e Doutorado}

Esta categoria temática emergiu da busca pela compreensão da maneira como os estudantes de Pós-Graduação de Mestrado e Doutorado se organizam no seu cotidiano.

Ao questionamento de: Como são seus momentos de lazer com a família? Estes momentos ficaram evidentes nas seguintes falas:

Eu tento me organizar de forma que eu estude e faça qualquer atividade durante a semana e final de semana eu tento tirar pra mim, não podendo tirar o final de semana eu tento, pelo menos, um 
ou dois dias na semana inverter, se eu tiver que ficar um final de semana inteiro trabalhando, eu separo um momento pra viver pra família, para as pessoas que eu gosto e pra ter pra mim, no mínimo um dia, sabe, eu procuro organizar, como uma forma pra mim até visão de saúde mental. [...] eu tento organizar de forma que eu fique a semana mesmo fazendo tudo que é necessário e final de semana, pelo menos, principalmente domingo é um dia meio sagrado assim, de fazer alguma coisa que eu esteja a fim mesmo ou nada (E1).

Minha organização é neste momento semanal, pois além das atividades acadêmicas devemos ter atividades de convívio social, com a família e de lazer [...] conversar sobre assuntos diversos do cotidiano, pois, por vezes, eu sinto que a academia nos sequestra dos assuntos comuns, $e$ tento tomar cuidado e me preocupo em perceber que tenho que interagir com outros assuntos, a exemplo, saber de coisas que são noticiadas nas TVs, pois deste modo penso que consigo uma interação que não seja vazia, com pessoas que não são da academia, e, portanto, não gostam ou não querem falar de teorias, teóricos ou de metodologias, assuntos comuns no nosso dia a dia de doutorando [...]. Para o lazer, reservo alguma noite em especial e os finais de semana, quando possível (E2).

Como é possível perceber, mesmo com as atribuições e demandas do dia a dia, os alunos representados por E1 e E2 organizam-se para o lazer, família e ter um momento para desligar das funções estritamente acadêmicas. Destaca-se nesse momento que a família sempre foi considerada rede de apoio para estudantes, em razão dos vínculos criados, bem como as implicações para o desenvolvimento humano (Dessen; Polonia, 2007).

Ademais, é importante que o estudante possa contar com uma rede familiar de apoio, visto que ele vive uma demanda intensa como pós-graduando. Este sente necessidade também de dispor de um tempo para si, especialmente no que diz respeito ao lazer. Em estudo realizado com estudantes de Enfermagem, o lazer foi destacado como promoção da saúde integral, com algumas funções primordiais: de descanso, de divertimento, distração, recreação, entretenimento e de desenvolvimento da personalidade (Santos; Radunz, 2011).

Em relação ao dia a dia com amigos e família, percebe-se que os estudantes conseguem separar um tempo, mesmo que reduzido, ou seja, à noite, ou final semana ou um dia qualquer para estar com outras pessoas que não sejam do mundo acadêmico, no entanto afirmam que existe uma cobrança por parte da família e amigos em relação ao tempo. Ao serem interrogados, referiram que somente discutem sobre tal assunto quando estão com alguém ligado à academia e que vivencia a mesma situação. Quando estão com a família e amigos procuram não falar sobre isso, como podemos constatar no depoimento a seguir:

\begin{abstract}
Quando visito os familiares, procuro deixar a academia aqui, vou para o quintal, faço atividades que fazia quando estava em casa com meus pais. Procuro desligar e dar atenção a eles, mesmo porque eles não estão interessados nos assuntos da academia, mas nos meus assuntos pessoais. Os amigos idem, a não ser que sejam do meio acadêmico, aí rola uma discussão [...] (E1).
\end{abstract}

Tem um distanciamento, no processo de doutoramento [...] eu acho que tem muita cobrança, a familia cobra, indiferente de grau ou de pai, mãe, de casamento, seja o que for, tem uma cobrança em cima disso porque a gente tem que se afastar, é necessário um momento de afastamento porque é muito estudo, muita leitura, muitas atividades, acaba se afastando, mas eu acho que se você colocar regras e te organizar, consegue levar as duas coisas concomitantes, mas eu não tenho a mesma frequência de visitas, a mesma frequência de estar junto como eu tinha antigamente, o doutoramento ele te ocupa tempo que te distancia um pouco da tua família, tu mantém mais por telefone, por mensagem de face (referindo-se ao facebook), seja o que for, mas te distancia do contato direto, que pra mim é uma coisa mais importante, o contato entre as pessoas ele (doutorado) 
dificulta isso. E quando consigo estar com eles esqueço a academia e curto o momento com eles (E2).

[...]. A preocupação que tenho é de reconhecer o cotidiano dos familiares, auxiliar em todas as questões quando possivel, mas não é uma tarefa fácil, às vezes sou incompreendido por ter que ficar muito tempo em leituras, resumos, viagens, trabalhos, orientações, pesquisas e relatórios, tarefa que não faz parte do cotidiano da família, mas os momentos que estou com eles, assim como com os amigos, procuro não falar assuntos do Doutorado, a não ser que seja um amigo do meio, aí sempre há uma conversa ou outra (E3).

A cobrança por parte dos familiares e amigos pode ocorrer em virtude das intensas demandas da Pós-Graduação, pois o tempo ficou mais restrito. É necessário muito tempo dedicado à leitura, viagens, atividades de pesquisa e que antes não faziam parte da rotina.

Cursar Mestrado ou Doutorado é um desafio, uma vez que os estudantes vivem em geral um mundo diferente do cotidiano familiar e com muitas demandas, ficando difícil, muitas vezes, a interação, fato que gera cobrança em relação à atenção dispensada aos familiares. Pesquisa de Voltarelli (2002) vai ao encontro dos resultados deste estudo ao constatar que os estudantes veem-se diante de dificuldades como a ausência de tempo, tanto para o estudo quanto para a vida particular.

Em qualquer universidade ou área do seu interesse, terá de gerir um significativo volume de trabalho e equilibrar seus compromissos de estudo com suas outras responsabilidades. Para os estudantes de Pós-Graduação com famílias, manter este equilíbrio pode ser uma tarefa realmente difícil.

Contrapondo este fato, estudo de Santos e Radunz (2011) descreve que a família ouve, dá apoio e incentiva a continuar lutando em qualquer situação. Assim, ao tentar o equilíbrio entre as atividades acadêmicas e família, estes estudantes de Pós-Graduação buscam também um suporte para as demandas produzidas na sua formação e a aceitação de sua ausência familiar em alguns momentos de imersão ao estudo.

Uma pesquisa de Faro (2013), com o objetivo de identificar os principais estressores da Pós-Graduação stricto sensu e determinar o índice de estresse em estudantes de Mestrado e Doutorado no Brasil, relatou que os fatores estressantes, como a interferência da demanda dos estudos sobre outros aspectos de sua vida, são uma das queixas mais frequentes dos pós-graduandos. Além disso, outro resultado apresentado foi que $65,2 \%$ deles não conseguem compatibilizar os estudos com a vida pessoal e familiar, o que gera uma alta carga de estresse.

A demanda dos estudos diminui o tempo que os estudantes poderiam estar com os seus, estressando-os por se verem diante de uma situação em que, muitas vezes, é incompreendido pela família, visto esta constituir, como já mencionado, uma rede de apoio importante aos estudantes.

Em relação à alimentação podemos observar que a maioria dos entrevistados procura fazer uma alimentação equilibrada:
É uma coisa que eu cuido [...], eu acho que eu me alimento bem [...], procuro comer comida e não fazer tanto lanche, procuro respeitar os horários mesmo com todas as dificuldades; assim é o mo- mento, eu paro, eu sei que eu tenho que comer, entende, é uma coisa minha assim, eu priorizo, não tem aquela coisa, ah, vamos ter que fazer um trabalho, hoje vou fazer um lanche, é uma loucura, não, então eu não vou fazer o trabalho, entende, eu respeito o meu corpo em relação a isso (E1).

Eu tento manter uma regra, comer muitas saladas ao meio dia, pois geralmente temos alguma atividade à tarde também e os alimentos muito pesados causam aquela sonolência pós-prandial. Tem dias que é mais complicado por causa das reuniões do programa cedo da tarde, mais constantes nas segundas, nestes dias por vezes o sanduíche salva o almoço, mas tento fazer as refeições normais. Diariamente, muita água e café (E2). 
A alimentação é algo que valorizo muito [...], pois ela nos permite a energia necessária para a rotina pesada do dia a dia. Como tenho o auxílio e preocupação da minha mãe, procuramos fazer uma alimentação saudável e baseada na ingesta de verduras, legumes, frutas e carnes; com comidas preparadas com pouco sal e gordura e também frescas. Faço sempre refeições fracionadas de 2/2h, com o café da manhã, lanche no meio da manhã, almoço, café da tarde e algum lanche el ou comida à noite e a ingesta hídrica é constante (E5).

Em uma alimentação saudável é imprescindível que a dieta tenha variedades para manter o peso ideal e ainda obter todos os nutrientes de que o corpo necessita, de forma que a deficiência de um nutriente em alguns alimentos seja compensada por sua presença em outros. Por isso, mesmo com o corre-corre do dia a dia é importante uma organização neste sentido.

É importante seguir os horários recomendados de alimentação essencial no dia a dia, evitando a substituição por lanches rápidos, pois estes reduzem a ingestão de alimentos tradicionais, que são fontes importantes de vitaminas, minerais e fibras, o que pode acarretar problemas de saúde futuros quando há essa substituição por alimentos de alta densidade energética (Ramalho; Dalamaria; Souza, 2012). A pouca variedade, os desequilíbrios na qualidade e na quantidade de alimentos disponíveis, assim como o padrão irregular da ingestão alimentar, podem afetar profundamente a saúde.

Observa-se que os estudantes conseguem reorganizar sua vida para uma alimentação regular, raras vezes saem da rotina habitual, no entanto o estudante E5 mantém uma alimentação adequada, com frutas, verduras, legumes, carnes, ingesta hídrico, refeições de duas em duas horas, fator importante para a manutenção de uma boa qualidade de vida.

Estudo de Souza, Bastos e Oliveira (2014) revela que no caso de estudantes que trabalham durante o dia e estudam à noite, a qualidade das refeições ocupa um segundo plano, e são poucos os que conseguem, mesmo trabalhan- do 8 horas por dia, ter uma boa alimentação. Both, Franz e Busnello (2012) alertam que os desequilíbrios, a pouca variedade na quantidade e qualidade, bem como o padrão irregular da ingesta de alimentos podem afetar a saúde visto que, quanto mais ativa e saudável uma pessoa for, menos terá limitações físicas e mais chances de sobrevida.

O estudante, muitas vezes, é cercado de demandas e isso contribui para a dificuldade em manter um equilíbrio alimentar. Neste estudo, os entrevistados, com dedicação exclusiva à Pós-Graduação, seja na qualidade de bolsistas e/ou licença para o estudo, podem se organizar melhor, e são raras as vezes que saem da rotina alimentar.

É importante, também, a atividade física aliada à boa alimentação. Os entrevistados relataram que procuram fazer algum exercício entre os trabalhos estudantis:

Faço, faço natação e pilates atualmente, uma vez por semana cada um e pretendo continuar e se puder fazer mais um pouco ainda pretendo fazer, que é uma coisa que muda o meu foco, e quanto retorno, amplia, entende? No momento que estou estressado, vou lá, relaxo e volto com outra forma de pensar, então mesmo que pra visão de muitas pessoas fazer exercício físico é tomar um tempo da tua vida, [...] pra mim é um ganho, volto muito melhor, a minha forma de pensar [...] (E1).

Eu faço caminhada diariamente, geralmente duas vezes por dia, e sempre que preciso sair para fazer algo, procuro ir a pé para exercitar-me e dinamizar o tempo. Iniciei na academia, mas devido a não poder ir nos horários combinados, desisti e preferi caminhar, que posso ir a hora que achar melhor (E3).

Faço algumas caminhadas sempre que posso, antes da Pós fazia caminhada três vezes por semana, depois que iniciei o curso, planejei frequentar a academia, mas não fiz nada ainda, pretendo logo iniciar este cuidado, mas acredito que o exercício da caminhada faz quase que diariamente em menos tempo (E4).

Pode-se observar pelos relatos que os estudantes realizam alguma atividade física, ou seja, natação, pilates e caminhada. O partici- 
pante E1 relata que utiliza os exercícios físicos como uma maneira de relaxar, melhorar o estresse e esquecer um pouco as atividades rotineiras. As caminhadas mencionadas pelas participantes E3 e E4 são essenciais para o bom funcionamento do organismo. Estes exercícios auxiliam na melhoria da qualidade de vida dos estudantes, pois além de meios de prevenir os males da inatividade produzem um grau de relaxamento, visto que, muitas vezes, a demanda dos estudos prejudica este autocuidado.

Nos últimos anos várias pesquisas comprovam que boa parte da falta de saúde é causada pela ausência de atividade física (Martins et al., 2010). Por meio da consciência e de mais informações a respeito de cuidados para com a saúde, que incluem maior movimentação corporal, as pessoas estão mudando seus hábitos de vida, daí a importância de dedicar um tempo à atividade física.

A prática regular de atividade física também deve fazer parte das metas de melhoria do estilo de vida dos estudantes, pois esta é uma ferramenta de auxílio na promoção de saúde (Soar; Silva; Lira, 2012). Esta prática reduz em 35\% o risco de morte por doenças cardiovasculares e em 33\% a mortalidade por todas as causas. Neste sentido, deve-se estimular continuamente que as pessoas sejam ativas fisicamente em todas as etapas da vida (Silva; Saenger; Pereira, 2011).

A prática de atividade física, seja ela qual for, torna-se um meio de promoção da saúde; toda a população deveria buscar melhoria na qualidade de vida, visto que a prática regular de atividade melhora a saúde, prevenindo problemas como diabetes, hipertensão, doenças cardiovasculares. Torna-se fundamental evitar o sedentarismo, bastante presente nos dias atuais. Além do mais, a prática de atividade física, juntamente com uma alimentação adequada e equilibrada, previne o envelhecimento precoce, pois afasta os radicais livres, precursores de envelhecimento (Both; Franz; Busnello, 2012).
O exercício físico pode ser considerado, em muitos momentos, como forma de lazer, pois inibe o estresse que pode advir de uma rotina de estudos. Ressalta-se, entretanto, que o ideal seria uma prática regular aliada a uma dieta equilibrada, conforme as necessidades do organismo de cada pessoa.

Quando entrevistados sobre os horários de descanso, a maioria referiu que procura reservar um tempo para isso quando está em casa:

Bem, meus períodos de descanso são à noite, quando chego em casa, e em alguns dias que posso ter um almoço mais tranquilo com a família ou com amigos. Não tem um dia certo, tem dias que o corpo e a cabeça pedem, e penso que é importante pegar sol, ler outros assuntos, outros livros que não estão ligados à academia, conversar com os amigos, rir muito, pois temos que ter as válvulas de escape. Gosto muito de sentar em um banco qualquer e ver a vida passar, valorizar o momento que é meu e também às vezes agradeço muito pelas lutas e conquistas [...] (E2).

Meu descanso é geralmente à noite, ou até finais de semana quando estou em casa com a família, procuro em alguns momentos descansar ao lado deles, desligar um pouco da academia, meditar, fazer outras coisas [...], mas é dificil, durante o dia quando tenho sono, se consigo cumprir as demandas, procuro dormir um pouco, relaxar (E4).

Algumas vezes tenho maiores periodos de descanso, depende muito da demanda de trabalho, porém no periodo da noite durmo cerca de 7 a 8 horas, além disso, gosto de fazer uma sesta pós- almoço quando possível, em torno de uma hora. E nos finais de semana alterno o tempo entre o estudo e o lazer, a depender do quanto rendi durante a semana e dos compromissos a serem cumpridos. (E5)

Podemos observar que o relaxamento, a meditação, ler livros que não estejam ligados à academia, estar com a família, pegar sol, agradecer pelas conquistas diárias, conversar com amigos, rir, e, até mesmo o período de sono é relatado por estes estudantes como momentos de descanso. 
Uma das melhores formas de manutenção das energias do corpo é pelo sono. Se se ficar muito tempo sem dormir, começam os efeitos colaterais, como dores musculares, cansaço, indisposição, imunidade baixa (Teixeira et al., 2007; Cardoso et al., 2009). Em geral recomenda-se de 7 a 8 horas de sono por dia para os adultos. O trabalho é considerado um sincronizador social do ciclo vigília/sono das pessoas de modo geral. Em um estudo foi apontada uma média de duração do sono de 7,1 horas para jovens trabalhadores, ao passo que aos não trabalhadores apresenta-se uma média de 8,6 horas nos dias com aula (Pereira et al., 2011).

Estudo de Peres e Andrade (2005) revela a existência de uma heterogeneidade das atividades extracurriculares, mas, independentemente desta diferença, identificou-se sentimentos de culpa diante da necessidade de conciliar o tempo livre para descansar, praticar exercícios físicos, cuidar da rotina acadêmica ou se envolver intensamente com tantas atividades extracurriculares.

O período de descanso ajuda a aliviar a fadiga, o estresse, o cansaço do dia a dia. Principalmente quando há períodos de exaustão, é necessário desligar das atividades rotineiras para descansar, seja da maneira que o estudante optar. $\mathrm{O}$ cérebro exige um tempo de descanso para permanecer focado e gerar suas ideias.

Nosso estudo contribuiu para que estes alunos fizessem uma reflexão a respeito da vida diária, de como estão vivendo este momento, pois os assuntos abordados são aspectos rotineiros de muitos deles, e que, em muitas vezes, não são respeitados. A alimentação, exercícios físicos, o descanso, o lazer, fazem parte da rotina dos alunos de Mestrado e Doutorado. Além das atividades da Pós-Graduação, eles devem dinamizar o tempo para atividades que melhorem a qualidade de vida e desviem o foco dos estudos, como estar com a família, com os amigos, ler um livro, meditar, relaxar, entre outras.

\section{CONSIDERAÇÕES FINAIS}

As atividades diárias de alunos do Mestrado e Doutorado baseiam-se em uma rotina intensa de estudos, pautada em leituras frequentes e com a escrita da dissertação e/ou tese, mas, mesmo assim, podemos observar e constatar por meio das falas que a maioria dos estudantes/participantes concilia e disponibiliza tempo para o seu entorno social, bem como se organiza para estar com a família e amigos, realizando atividades de lazer e descanso e incorporando uma alimentação saudável, na maioria das vezes. Em contrapartida ao tempo dedicado à família, permanece uma cobrança constante por parte dos familiares e amigos para permancerem mais tempo com eles, o que pode estar associado, em alguns casos, à falta de compreensão dos amigos e da família em aceitar a carga de tempo dedicada à Pós-Graduação, e também ao fato de os pós-graduandos não programarem o seu tempo e dividi-lo com outros afazeres cotidianos, como estar com a família, passear e sair com os amigos, conforme faziam antes de entrar para o programa de Pós-Graduação.

Este estudo evidencia a necessidade de políticas nos programas de Pós-Graduação que auxiliem os estudantes a melhorar a qualidade de vida, proporcionando, incentivando e criando espaços de discussão e compartilhamento de experiências no que se relaciona ao vivido por eles no dia a dia, para que em ações conjuntas possam dispor de condições de melhor cuidar de si, evitando, desta maneira, o estresse presente na vida de muitos deles.

Como limite para este estudo cita-se a falta de pesquisas que valorizem a temática do cotidiano dos pós-graduandos em Enfermagem, de forma a levar em consideração todas as mudanças ocorridas no dia a dia dos mestrandos e doutorandos e o impacto para a vida pessoal e profissional. Assim, esta pesquisa propôs-se a contribuir para o tema de modo a incentivar 
que outros estudos sejam realizados, com a abordagem direcionada aos discentes de Mestrado ou Doutorado em Enfermagem.

\section{REFERÊNCIAS}

ALMEIDA, M. C. P de et al. Perfil da demanda dos alunos da pós-graduação stricto sensu da Escola de Enfermagem de Ribeirão Preto, da Universidade de São Paulo. Revista Latino-Americana de Enfermagem, v. 12, n. 2, p. 153-161, 2004.

BARDIN, L. Análise de conteúdo. 7. ed. Lisboa: Edições 70, 2011.

BOFF, L. Saber cuidar: ética do humano: compaixão pela terra. 20. ed. São Paulo: Petrópolis, RJ: Vozes, 2014.

BOTH, M.; FRANZ, L. B. B.; BUSNELLO, M. $\mathrm{B}$. Índice de qualidade da dieta de frequentadores de academia. Revista Contexto \& Saúde, Ijuí: Ed. Unijuí, v. 12, n. 23, p. 2-8, 2012.

BRASIL. Ministério da Educação; Coordenação de Aperfeiçoamento de Pessoal de Nível Superior; Diretoria de Educação a Distância; Coordenação-Geral de Programas e Cursos em Ensino a Distância. Documento Técnico - análise da Lei de Direitos Autorais Brasileira, 2014. Disponível em: $<$ http:// itsrio.org/wp-content/uploads/2015/07/Consultoria-cc.pdf>. Acesso em: 20 jun. 2015.

. Coordenação de Aperfeiçoamento de Pessoal de Nível Superior (Capes). Relatório de gestão 2009. Brasília, DF, 2010.

Instituto Nacional de Estudos e Pesquisas Educacionais Anísio Teixeira (Inep). Educação superior no Brasil - 10 anos pós-LDB. In: BITTAR, M.; OLIVEIRA, J. F.; MOROSINI, M. (Orgs.). Brasília: Inep, 2008. 348 p.: il. - (Coleção Inep 70 anos, v. 2). Disponível em: $<$ http://www.oei.es/ pdf2/educacao-superior-brasil-10-anos.pdf $>$. Acesso em: 31 jan. 2015.

BUDÓ, M. L. D. A prática de cuidados em comunidades rurais e o preparo da enfermeira. (Teses de Enfermagem). Florianópolis-SC: UFSC/PEN, 2002.
CARDOSO, H. C. et al. Avaliação da qualidade do sono em estudantes de Medicina. Revista Brasileira de Educação Médica, v. 33, n. 3, p. 349-355, 2009.

CISCON-EVANGELISTA, M. R.; SOUZA, M. L.; MENANDRO, P. R. M. Agradecimentos: dificuldades, conquistas e rede social de apoio de estudantes de Pós-Graduação stricto sensu. Revista da SPAGESP, v. 16, n. 1, p. 12-27, 2015.

DESSEN, M. A.; POLONIA, A. C. A família e a escola como contextos de desenvolvimento humano. Paidéia, v. 17, n. 36, p. 21-32, 2007.

DYRBYE, L. N. et al. Burnout and serious thoughts of dropping out of medical school: a multiinstitutional study. Academia Médica, v. 85, n. 1, p. 94-102, 2010.

ERDMANN, A. L. Desafios da enfermagem na Capes: produtos altamente qualificados. Revista Escola de Enfermagem USP, v. 42, n. 2, p. 216-217, 2008.

FARO, A. Estresse e estressores na pós-graduação: estudo com mestrandos e doutorandos no brasil. Psicologia: Teoria e Pesquisa, v. 29, n. 1, p. 51-60, 2013.

LOUZADA, R. C. R.; SILVA FILHO, J. F. Formação do pesquisador e sofrimento mental: um estudo de caso. Psicologia em Estudo, v. 10, n. 3, p. 451461, 2005.

MARTINS, M. C. C. et al. Pressão arterial, excesso de peso e nível de atividade física em estudantes de universidade pública. Arquivos Brasileiros de Cardiologia, v. 95, n. 2, p. 192-99, 2010.

MINAYO, M. C. S. O desafio do conhecimento: pesquisa qualitativa em saúde. 12. ed. São Paulo; Rio de Janeiro: Hucitec, 2010.

OSSE, C. M. C.; COSTA, I. I. Saúde mental e qualidade de vida na moradia estudantil da Universidade de Brasília. Estudos de Psicologia, Campinas, v. 28, n. 1, p. 115-122, 2011.

PEREIRA, E. F. et al. Sono, trabalho e estudo: duração do sono em estudantes trabalhadores e não trabalhadores. Caderno de Saúde Pública, v. 27, n. 5, p. 975-984, 2011.

PERES, C. M.; ANDRADE, A. S. Atividades extracurriculares: representações e vivências durante a formação médica. 2005, Dissertação (Mestrado) - Ribeirão Preto, SP, Livro de Artigos, 2005. 
RAMALHO, A. A.; DALAMARIA, T.; SOUZA, O. F. Consumo regular de frutas e hortaliças por estudantes universitários em Rio Branco, Acre, Brasil: prevalência e fatores associados. Caderno de Saúde Pública, v. 28, n. 7, p. 1.405-1.443, 2012.

RODRIGUES, R. A. P. et al. Educação do doutorado em enfermagem no Brasil. Revista Latino-Americana de Enfermagem, v. 16, n. 4, p. 665-671, 2008. Disponível em: $<$ http://www.scielo.br/pdf/ rlae/v16n4/pt_03.pdf $>$. Acesso em: 3 nov. 2014.

SANTOS, V. E. P.; RADUNZ, V. O cuidar de si na visão de acadêmicas de enfermagem. Revista Enfermagem Uerj, v. 19, n. 1, p. 46-51, 2011.

SCOCHI, C. G. S. et al. Pós-graduação Stricto Sensu em Enfermagem no Brasil: avanços e perspectivas. Revista Brasileira de Enfermagem, v. 66, n. especial, p. 80-89, 2013.

SILVA, T. R.; SAENGER, G.; PEREIRA, E. F. Fatores associados à imagem corporal em estudantes de Educação Física. Motriz, v. 17, n. 4, p. 630-639, 2011.

SOAR, C.; SILVA, P. S.; LIRA, J. G. Consumo alimentar e atividade física de estudantes universitários da área de saúde. Revista Univap, v. 18, n. 31, p. 41-7, 2012.

SOUZA, J. V.; BASTOS, T. P. F.; OLIVEIRA, M. F. A. Perfil dos alunos universitários dos cursos de Educação Física e Fisioterapia em Relação à Alimentação e à Atividade Física. Revista Práxis, v. 6, n. 11, p. 2.176-9.230, 2014. Disponível em: $<\mathrm{http} / / /$ web.unifoa.edu.br/praxis/ojs/index.php/praxis/article/view/49>. Acesso em: 10 abr. 2015.

TEIXEIRA, L. R. et al. Sleep and sleepiness among working and nonworking high school evenings studentes. Chronobiology International, v. 24, n. 1, p. 99-113, 2007.

VOLTARELLI, J. C. Estresse e produtividade acadêmica. Revista Medicina Ribeirão Preto, v. 35, n. 4, p. 1-2, 2002.

Recebido em: 19/10/2015

Aceito em: 24/11/2015 